\title{
Special Education: Teaching Geometry with ICTs
}

\author{
https://doi.org/10.3991/ijet.v15i06.11242 \\ Viktoriya N. Galitskaya ${ }^{(凶)}$, Athanasios S. Drigas \\ N.C.S.R. "Demokritos", Athens, Greece \\ vgalitskaya@yahoo.gr
}

\begin{abstract}
Geometry is a very important field of mathematics which is crucial for the understanding of space. From an early age, children observe objects that correspond to geometric shapes and learn the position they occupy in space (above, below, etc.). It is a demanding lesson that requires imagination and combinational thought. With the introduction of technology in education, geometry became more accessible to students, because through it pupils can now visualize figures, study and process them.
\end{abstract}

Keywords - ICTs, Geometry, special education, learning disabilities

\section{Introduction}

Geometry helps students to analyze and explain the world. It supplies them with the necessary tools which they can then apply to other areas of mathematics (A. O. Zerem, 2012).

Based on Piaget, children at the age of 18 months should understand the location of objects in space, until they reach 5 years of age they should grasp the concept of single shapes and 7-8 years old understand vertical and straight lines [1].

The impact of the introduction of ICTs in education has been studied since the 1970s and more and more researchers are convinced that they can improve the teaching process [2]. Van de Walle (1998) highlighted three ways in which technology is changing the teaching of mathematics:

- It reduces the time needed for the execution of a mathematical act or charting that a student can then use to interpret the result.

- Students can understand different concepts, such as three- dimensional graphs by visualizing them.

- Some mathematical skills become simpler and more accessible, such as statistical analysis [3].

Berg (1997) and Shekhar (2012) have used the term "ageometria" and "ageometrsia" to describe the difficulty students have to understand geometry [4].

However important the teaching of mathematics is in general education it is more important and necessary in special education. In recent years great progress has been made in creating ICTs applications for students with specialized training needs so 
they can too have equal rights in education5. The internet is another educational tool that helps to improve the mathematical skills of children [6].

Some students with special needs have difficulty in concentrating their attention on the relevant aspects of learning materials. Strategies that may help these students understand geometry are using larger-than-normal sizes for diagrams and print materials, using color or clear areas to separate important aspects of problems, allowing enough time for students to process visual material, and using manipulatives. Teachers should guide students to adopt these strategies for their independent use [7].

According to the theory of Pierre van Hiele and Din van Hiele-Geldof, students are divided into levels based on their geometric perception.

Level 1 (Visualization): Students identify figures only by appearance (topology), they make decisions based on perception, not reasoning.

Level 2 (Analysis): Students see figures as collections of properties. They can recognize and name properties of geometric shapes, but they cannot see a connection between these properties.

Level 3 (Abstraction): Students realize the connection between properties and figures.

Level 4 (Deduction): Students can construct proofs, understand the role of postulates, theorems and proof.

Level 5 (Rigor): Students understand the necessity for rigor and the formal aspects of deductions [8].

Many applications and technologies have been created to enable children with visual, hearing or mobility impairments to study and design geometric shapes. The National Council of Teachers of Mathematics (NCTM, 2015) underlined the importance of technology integration in the teaching of mathematics.

\section{Children with Visual Disability}

\subsection{Educational games on the computer}

For special education educators specializing in visually impaired children, technology was the only way to teach writing and reading. However, this is not the case for Geometry since it requires touch as the input perception channel. The research was made and various applications and games were developed to identify:

- The coordinates of a point in a place

- The length, orientation, starting point locations

- Polygons and curves (recognition, orientation)

All the above, researchers tried to teach with the help of 3 games: Simon, Points and Concentrations.

Simon: In this game, the participant hears sounds that differ in tone and each time it comes from another position and the participant has to reproduce the correct sequence in the correct position on the graphic table. 
Points: This game has two different ways of playing. In the first one, the participant listens to two sounds that were different in their position on the sound screen and the participant should make the line that connects the two points. In a second way, the participant hears auditory cues that make the line and the player has to locate the starting and ending points of the line.

Concentrations: This game has three different levels. The goal of the game is to find the pair of eight shapes. The participant is given 8 shapes in series with the help of sounds that are constantly changing direction to form different shapes eg. square, rectangle, rectangle, circle, square, triangle, circle, triangle. The student then has to choose the proper combination that corresponds to the same shapes e.g. $(\{1 \mid 5\}$, $\{2 \mid 3\},\{4 \mid 7\},\{6 \mid 8\}\}$.

From points to figure: This game is a combination of the Simon and Points games and gives the opportunity in two participants to play together.

These games were tested with four blind adults who knew geometric figures and three of them with musical experience. They had one hour to complete the whole game level, and each level was defined using the following figures:

Level 1: Horizontal line, vertical line, a diagonal line starting at the upper left corner, a diagonal line starting at the bottom left corner

Level 2: One diagonal, square, triangle, and circle

Level 3: Square, rectangle, circle, oval.

The aim was to associate the sounds with the corresponding shapes.

At the end of the process, all participants recognized and were able to match all the shapes except the circle and the oval. Additionally, the results showed that the above games ware more effective for the participants that were blind since birth, and had musical experience [9].

In another research that was conductive by Roth et al (2010) IDEA was used. In this game, the user can move his/her finger around the digital graphics while the system responds with audio feedback which informs the user about the feature or kind of feature he has touched. This tool was designed to teach basic geometry concepts, and help students understand shapes. This model corresponds to the tunnel vision that the blind user has when he/she explores a tactile image with his/her finger. Furthermore, users can ask for a sonic or textual rendering of the contour attributes such as its direction, or the location of its extremities [10].

\subsection{Mobile and tablet application}

One of the tools that help blind children learn geometry is based on the Android application. This app allows children to make freehand drawings and play with geometry by vibrotactile. The freehand drawing gives students the opportunity of perceiving an object. The two modes are activated by a double touch 'draw' and 'sense'. The canvas drawing area occupies most of the place on a screen. On the right students can find the button for color selection and on the left navigation. Each button could be identified through phonic feedback when students move their finger on the screen, while a long press activates the selection. In the second game named "play with the geometry" students have to recognize shapes. Children can explore with their finger 
the screen and that causes a tablet vibration if the fingertip position falls under a pixel included in the drawing, while no feedback is provided if the fingertip touches a white pixel. A third game is called "topology game" in which students play with concepts such as inside of, nearly, etc [1] [11].

Other researchers developed two applications named "GEOMETRICVOICE and MATGRAFVOICE" for the treatment and generation of geometric figures and math functions, through a Braille printer designed for visually impaired people.

Step of GEOMETRICVOICE:

- Selection of the geometric figure

- Insertion of the parameters

- Additional information of axes

- Computing calculation and design

- Print geometric figure in ink, Braille and with reliefs.

Matgrafvoice: Is software for mathematical treatment that gives the ability to design any kind of mathematical function and produce their graphic representation. The system is communicating through speech synthesis. In this way, the editor can enter text and has the option to print it in Braille [12]

\subsection{Raised- line paper drawing and programmable tactile displays}

Sixteen visual impaired children participated in this research from which five were males. Eight of them were blind and eight had low vision, their ages ranged from 8 to 22 years. During the sessions all participants had their eyes closed to block any external factors and they performed four different tests. Two tests were done using raisedline paper drawings and two using programmable tactile displays. The first task of raised- line paper drawing consists of two tests, the tactile symbol recognition and enumeration in noise (in the paper spatial test) and the second task is the memory spanning of sequences of tactile symbols (paper spatiotemporal test). The first task of programmable tactile displays has to do with the recognition of geometrical shapes and localization in noise. In the second test of programmable tactile displays, participants should memorize spatial dispositions. Blind and low vision children and adolescents showed a significant performance enhancement in spatial tasks using programmable tactile displays. In conclusion, this preliminary study indicated that visually impaired youngsters understood and benefited from programmable tactile displays in educative and rehabilitative contexts [13].

\section{Deaf or Hard of Hearing Students}

Based on Nunes and Moreno (2002) deaf children will fail in mathematics because they have reduced opportunities for incidental learning, and it is difficult for them to make inferences involving time sequences [14].

Furthermore, teachers find difficult to teach students basic mathematical concepts in sign language or via interpreting [15]. 
Experiment with WiTec (wireless technology-enhanced classroom) was conducted with 7 hard of hearing students of moderate to low educational level in a high school in order to learn polynomials and geometry. Fifty questions from the competency test of mathematics for Taiwanese hard of hearing students (Lin \& Li, 1996) were adopted to measure the students' mathematics capacity. The courses lasted two semesters with the help of WiTec which was given to students and teachers on touchscreen devices. It turned out that children found it easier to understand the lesson with the use of WiTec. WiTec allowed them to communicate directly with the teacher and this facilitated their communication and participation in the course [16].

Russell, Hoffmann and Higgins (2009) developed Nimble Tools that is a geometry assessment system. They tested it on deaf and hard of hearing children and the results showed that they preferred to use the online environment and the computer testing than paper-and-pencil [17].

\section{$4 \quad$ Students with Autism Spectrum Disorders}

Children with autism often have exceptional abilities in geometry and spatial. About 10 percent of children with autism have excellent spatial abilities. There are some applications suitable for the understanding of geometry for these children [18].

\subsection{Geometry snapshots}

In this application, the students see on the screen a part of a shape and they should find the other correct part from four multiple-choice. Students fit figures or combinations of figures that were turned or flipped.

\subsection{Mystery pictures}

This program teaches children shapes (their names) and asks students to match a given shape in different orientations. After that, they should build a picture with the help of the given figures.

\subsection{Shape parts 1 and 7}

The goal of this game is to make a figure using several given parts of geometrical shapes.

\subsection{The piece puzzle}

In this game, children must compose shapes to complete a puzzle18. 


\subsection{LEMA}

(Learning Environment on Mathematics for Autistic Children), I this research 7 students with an autism spectrum disorder (ASD) participated. All of them were males, aged 8 to 12 years. LEMA is a learning program that combines text, image and sound animations. It focused on learning two-dimensional and three-dimensional geometric shapes, perimeters and areas of planar figures, and planar isometrics. Only 4 out of 7 participants completed the research. Results showed that with the help of technology children in the autism spectrum improved their skills in comparison to children that were taught with conventional methods [19].

\section{Students with ADHD}

Students with ADHD have deficiencies in mathematics that have been related to attention deficits [20].

Kang and Zentall (2011) examined the impact of CAI (Computer Assisted Instruction) and the performance of students with ADHD in geometry. In the survey, 18 students with ADHD from second to fourth grade participated. Students tried to learn more about different geometry shapes and calculate the perimeter via computer monitor or pencil-and-paper. The research included 2D planar images and problems of increased difficulty and questions about the perimeter of 3D solid geometric shapes. The research has shown that students performance improved more with the help of the CAI than with pencil-and-paper method[21][22].

\section{$6 \quad$ Students with Learning Difficulties}

Cihak and Bowlin (2009) tried to teach 3 students with Specific Learning Disabilities, aged 15- 18 years, mathematics. They used video modeling to teach students step- by- step how to calculate the perimeter of squares/ rectangles, triangles/trapezoids, and various polygons. Students were shown video daily before the beginning of the school day through a tutoring program. Results showed that students after the completion of the research increased their geometry skills [5].

Satsangi and colleagues studies aimed specifically on how to learn the concepts of area and perimeter-based in the area of virtual manipulative instruction for students with learning disabilities. Their study included paper-and-pencil and virtual manipulative methods. For the intervention, a laptop was offered to students. In each session of the study, students were given geometrical shapes that had sides with single-digit length, without measurement units and 90 degrees angles. Students tried to solve problems about area and perimeter. During all sessions, students were permitted to use a four-function calculator and the virtual manipulative were accessed through a NLVM (National Library of Virtual Manipulatives). Results showed that the use of virtual manipulatives increased the performance of all three participants in solving area and perimeter mathematics problems more than the paper-and-pencil method [23]. 


\section{$7 \quad$ Students with Intellectual Disabilities}

Creech-Galloway and colleagues (2013) showed videos to teach high school students with Intellectual Disabilities how to use the Pythagorean Theorem. They used procedures with examples of real-life problems. Four students with intellectual disability participated in the research [24].

The application named "play and learn with mouse" works with Adobe Flash. One of the teaching modules is aimed at the introduction to basic geometrical figures and colors to students with the intellectual disorder. In one of the two modules students should select only the target shape and not the other projected shape (e.g. only the rectangle from a number of squares, rectangular). The module is then restarted and students should once again select another target shape (e.g. only rectangular). In the second module, students should find once more the target shape and in addition measure their number (e.g. 5 circles among rectangular, square, etc) [25].

\section{$8 \quad$ Students with Down Syndrome}

Several researchers have found that students with Down syndrome have greater enthusiasm for computer-assisted instruction.

One of the researches was conducted among 12 children with moderate intellectual disabilities. Sessions were daily during a 16 weeks period using an Android app named "HALTE". The application showed visual information to students while playing an audio recording. One of the activities involved geometrical shapes. The results of each student were automatically saved by the application. At the end of the survey, the results showed that children learned more effective through the specific application than conational methods [26].

Dixon and colleagues developed an application based on the PEAK-E Curriculum to teach two children with high- functioning autism. They taught them the names of shapes, their properties (e.g. number of sides), and how to recognize them through pictures. The five shapes included in the research were the pentagon, the hexagon, the heptagon, the octagon and the decagon [27].

\section{Children with General Learning Difficulties and Movement Problems}

Starcic and colleagues investigated how students with low fine motor skills that cannot draw independently or use the computer mouse and those with learning difficulties developed their geometry concepts. Their research was based on how the use of a TUI (Tangible User Interface) -assisted learning environment for geometry teaching. This research also included students from preprimary and primary school with low motor skills and learning disabilities. At the end of the sessions, all students could be actively involved in the teaching process of Geometry and were able to design figures [28]. 


\section{Teaching Children with Different Disabilities with ICTs}

In this study, 335 students with disabilities (autism, special learning difficulties, ADHD and other health problems) participated. They were taught with two instructional conditions EAI (Enhanced Anchored Instruction) and BAU (Business As Usual). EAI included computer-based interactive lessons, video-based and hand-on applied projects. BAU's teaching was focused on solving real-life problems, graphing of ordered pairs, concepts related to geometry. The results showed that EAI students scored higher than BAU students on three of four achievement measures[29].

\section{Conclusion}

The purpose of this article was to examine researches done on the teaching of geometry with the help of ICT to children in special education. It was found that children learn more easily and effectively in this way and that no child is excluded from the learning process despite their problems. Our aim should be that all ICTs means must be available in all schools.

\section{References}

[1] Buzzi, M., Leporini B. (2015). Playing with geometry: a Multimodal Android App for Blind Children. Retrieved from https://doi.org/10.1145/2808435.2808458.

[2] Drigas, A., Ioannidou, E. (2013). Special Education and ICTs. International Journal of Emerging Technologies in Learning (iJET), 8 (2). https://doi.org/10.3991/ijet.v8i2.2514

[3] Wiest, L. R. (2001). The role of computers in mathematics teaching and learning. Using Information Technology in Mathematics Education, 11, p. 41-55.

[4] Plerou, A. (2014). Dealing with Dyscalculia over time. International Conference on Information Communication Technologies in Education.

[5] Clinton, E. (2015). Using video modeling to teach academic skills to students with disabilities: A review of the literature. The International Journal of Applied Research, 1, p. 382390.

[6] Kelly, R. R. (2003). Calculating math problems: A comparative look at deaf and hearing students. Association of College Educators-Deaf and Hard of Hearing.

[7] Sliva JA. 2004. Teaching inclusive mathematics to special learners. Thousand Oaks, CA: Corwin Press.

[8] Accascina, G., Margiotta, G., \& Rogora, E. (2005). Making bad conjectures and. ICTMT7Bristol, p. 26-29.

[9] Roth, P., Petrucci, L., \& Theirry, P. (2000). From Dots to Shapes": an auditory haptic game platform. ICCHP 2000, International Conference on Computers Helping People with Special Needs. , p. 603-610.

[10] Roth, P., Petrucci, L., Assimacopoulos, A., \& Pun, T. (2000). Audio-haptic internet browser and associated tools for blind and visually impaired computer users. Proc. Workshop on Friendly Exchanging Through the Net, p. 57-62. https://doi.org/10.14236/ewic/ad1998.25

[11] Costa, 1., Correa, A., Leite, D., Zuffo, M., \& Lopes, R. (2015). Educadaisy: Accessible Digital Didactic Book on Tablets for People with Visual Impairment. IEEE International 
Conference on Consumer Electronics (ICCE'15). https://doi.org/10.1109/icce.2015.706632 $\underline{6}$

[12] León, L., Martini, L., \& Moreno-Chaparro, C. (2016). Tools for Teaching Mathematical Functions and Geometric Figures to Tactile Visualization through a Braille Printer for Visual Impairment People. Proceedings of IMCIC - ICSIT 2016.

[13] Leo, F., Cocchi, E., \& Brayda, L. (2017). The Effect of Programmable Tactile Displays on Spatial Learning Skills in Children and Adolescents of Different Visual Disability. IEEE Transactions on Neural Systems And Rehabilitation Engineering, 25 (7). https://doi.org/ $\underline{10.1109 / \text { tnsre.2016.2619742 }}$

[14] Nunes, T., \& Moreco, C. (2002). An Intervention Program for Promoting Deaf Pupils'. Achievement in Mathematics. Oxford University Press

[15] Adamo-Villani, N., Doublestein, J., \& Martin, Z. (2005). Sign Language for K-8 Mathematics. Educational Technology Systems, 3, p. 241-257. https://doi.org/10.2190/kub16m7x-nhy5-3bwg

[16] Chen-Chung, L., Chien-Chia, C., Baw-Jhiune, L., \& Jui-Wen, Y. (2006). Improving mathematics teaching and learning experiences for hard of hearing students with wireless technology-enhanced classrooms. American annals of the deaf, 151 (3).

[17] Israel, M., Marino, M., Delisio, L. L., \& Serianni, B. (2014). Supporting content learning through technology for K-12 students with disabilities. CEDAR Document IC-10

[18] Clements, D., \& Samara, J. (2006). Early Math: Young Children and Geometry. Special Education and Mathematics, p. 163-196.

[19] Almeida, A., Breda, A., \& Santos, M. (2016). Learning Environment for autism spectrum disorder: a universal approach to the promotion of mathematical reasoning. 7th International Conference on Software Development and technologies for Enhancing Accessibility and fighting, p. 162-169. https://doi.org/10.1145/3019943.3019967

[20] Zentall, S., \& Javorsky, J. (2007). Professional Development for Teachers. Behavioral Disorders, 32 (2), $\sigma \sigma .78-93$

[21] Kang, H., \& Zentall, S. (2011). Computer-generated geometry instruction: a preliminary study. Educational Technology Research and Development, 59 (6), p. 783-797. https://doi. org/10.1007/s11423-011-9186-5

[22] Botsas, G., \& Grouios, G. (2017). Computer-assisted instruction of students with ADHD and academic performance: a brief review of studies conducted between 1993 and 2016, and comments. European Journal of Special Education Research, 6.

[23] Satsangi, R., \& Bouck, E. (2014). Using virtual manipulative instruction to teach the concepts of area and perimeter to secondary students with disabilities. Learning Disability Quarterly, 38 (3), p. 174-186. https://doi.org/10.1177/0731948714550101

[24] Creech-Galloway, C., Collins, C., Knight, V., \& Bausch, M. (2013). Using a simultaneous prompting procedure with an iPad to teach the Pythagorean Theorem to adolescents with moderate intellectual disability. Research and Practice for Persons with Severe Disabilities, 38:222, p. 222-232. https://doi.org/10.1177/154079691303800402

[25] Zamfirov, M. (2011). Use of the educational software "play and learn with a mouse" in mathematics teaching of students with intellectual disorder in Bulgaria. journal.ecenter.uni-sofia.bg/f/downloads/2011/Broi_4/M.Zamfirov_ED.pdf.

[26] Felix, V., Mena, L., \& Maestre, G. (2017). A pilot study of the use of emerging computer technologies to improve the effectiveness of reading and writing therapies in children with Down syndrome. British Journal of Educational Technology. https://doi.org/10.1111/bjet. $\underline{12426}$ 
[27] Dixon, M., Belisle, J., Stanley, C., Daar, J., \& Williams, L. (2016). Derived Equivalence Relations of Geometry Skills in Students with Autism: an Application of the PEAK-E Curriculum. Spinger , 32, p. 38-45. https://doi.org/10.1007/s40616-016-0051-9

[28] Starcic, A., Cotic, M., \& Zajc, M. (2013). Design-based research on the use of a tangible user interface for geometry teaching in an inclusive classroom. British Journal of Educational Technology , 44 (5), p. 729-744. https://doi.org/10.1111/j.1467-8535.2012.01341.x

[29] Bottge, B., Ma, X., Gassaway, L., Toland, M., Butler, M., \& Cho, S. (2014). Effects of blended instructional models on math performance. Exceptional Children, 80, p. 423-437. https://doi.org/10.1177/0014402914527240

\section{Authors}

Viktoriya N. Galitskaya a research associate at N.C.S.R. "Demokritos", IIT- Net Media Lab \& Mind - Brain R\&D, Agia Paraskevi, 153 10, Athens, Greece

Athanasios S. Drigas is a Research Director at N.C.S.R. "Demokritos", IIT - Net Media Lab \& Mind- Brain R\&D, Agia Paraskevi, 153 10, Athens, Greece (e-mail: dr@iit.demokritos.gr).

Article submitted 2019-07-10. Resubmitted 2020-01-09. Final acceptance 2020-01-12. Final version published as submitted by the authors. 